\title{
Field Evaluation of Natural, Engineered, and Combined Resistance Mechanisms in Potato for Control of Colorado Potato Beetle
}

\author{
Joseph J. Coombs and David S. Douches ${ }^{1}$ \\ Department of Crop and Soil Sciences, Michigan State University, East Lansing, MI 48824 \\ Wenbin Li \\ Department of Plant Agriculture, University of Guelph, Biotechnology Division, Guelph, Ontario, Canada \\ $N 1 G 2 W 1$ \\ Edward J. Grafius and Walter L. Pett \\ Department of Entomology, Michigan State University, East Lansing, MI 48824
}

\begin{abstract}
ADDITIONAL INDEX wORDS. Solanum tuberosum, Leptinotarsa decemlineata, host plant resistance, Bacillus thuringiensis (Bt), cry3A, cry5 (crylIal), leptine glycoalkaloids, glandular trichomes
\end{abstract}

\begin{abstract}
The colorado potato beetle, Leptinotarsa decemlineata Say (Coleoptera: Chrysomelidae), is the leading insect pest of potato (Solanum tuberosum $L_{\text {.) }}$ in northern latitudes. Host plant resistance has the potential use in an integrated pest management program for control of colorado potato beetle. During the 1998 and 1999 seasons, field studies were conducted to compare natural (leptine glycoalkaloids and glandular trichomes), engineered (Bt-cry3A and Bt-cry5 transgenic potato lines), and combined (Bt-cry5+glandular trichomes) plant resistance mechanisms of potato for control of colorado potato beetle. Nine different potato clones representing five different host plant resistance mechanisms were evaluated under natural colorado potato beetle infestation at the Montcalm Research Farm in Entrican, Michigan. The Bt-cry3A transgenic lines, the high leptine line (USDA8380-1), and the high foliar glycoalkaloid line (ND5873-15) were most effective for controlling defoliation by colorado potato beetle adults and larvae. The Bt-cry5 line (SPc5-G2) was not as effective as the Btcry3A transgenic lines ('Russet Burbank Newleaf,' RBN15, and YGc3.1). The glandular trichome (NYL235-4) and Btcry5+glandular trichome lines proved to be ineffective. Significant rank correlations for the potato lines between the two years were observed for egg masses, second and third instar, and fourth instar seasonal cumulative mean number of individuals per plant, and defoliation. Egg mass and first instar seasonal cumulative mean number of individuals per plant were not strong indicators of host plant resistance in contrast to second and third instars or adults. Based on these results, the Bt-cry $3 \mathrm{~A}$ transgenic lines, the high leptine line, and the high total glycoalkaloid line are effective host plant resistance mechanisms for control of colorado potato beetle.
\end{abstract}

The colorado potato beetle, Leptinotarsa decemlineata (Say), is the most serious insect pest of potatoes (Solanum tuberosum L.) throughout the eastern and north central United States. Control of the colorado potato beetle has relied almost entirely on pesticides for over 125 years (Casagrande, 1987). Throughout its history, the colorado potato beetle has shown an ability to adapt to every insecticide used for its control (Forgash, 1985). Currently, it is reported worldwide to be resistant to 37 insecticides, including organophosphates, carbamates, organochlorines, pyrethroids, and hydrogen cyanide (Georgiou and Lagunes-Tejeda, 1991).

Bacillus thuringiensis $(B t)$ is an aerobic, gram-positive, soil bacterium that accumulates high levels of insecticidal proteins during sporulation (Barton and Miller, 1993; McGaughey and Whalon, 1992). Different $B t$ toxins target specific orders of insects and have no known detrimental effects on mammals or birds (McGaughey and Whalon, 1992). The insecticidal crystal proteins produced by $B t$ are products of single genes, which have been isolated, analyzed, characterized, cloned, and codon-modified to increase expression in plants (Adang et al., 1993; Perlak et al., 1993; Sutton et al., 1992). Transgenic plants deliver the Bt toxin with increased efficacy, reduced application costs, and minimal scouting

Received for publication 24 June 2002. Accepted for publication 13 Nov. 2002. This publication was made possible through support provided by the Michigan Agriculture Experiment Station and the National Potato Council. The research was also supported by the Office of USAID/CAIRO/AGR/A, under cooperative Agreement No. 263-0152 A-00-3036-00.

'Corresponding author; e-mail douchesd@msu.edu. needs compared to foliar $B t$ applications (Lambert and Peferoen, 1992). Currently, there are 40 major groups of $B t$ endotoxins, designated Cry1 through Cry40 with 108 holotypes (Crickmore et al., 2002), offering toxicity toward Lepidoptera, Coleoptera, and Diptera. The Bt-Cry3A protein is effective against Coleoptera (Adang et al., 1993; Perlak et al., 1993; Sutton et al., 1992) and BtCry5 (Cry1Ia1) is active against Lepidoptera and Coleoptera (Tailor et al., 1992).

Glandular trichomes and leptine glycoalkaloids are two natural host plant resistance mechanisms of potato that are candidates for pyramiding with $B t$-transgene(s). The presence of type A and B trichomes leads to entrapment and death of small-bodied insects (Gregory et al., 1986) and reduces developmental time, survival, and oviposition of colorado potato beetle (Casagrande, 1982; Wright et al., 1985; Yencho and Tingey, 1994). The trichomes of $S$. berthaultii Hawkes are associated with insect responses to host plant resistance including host avoidance, restlessness, reduced feeding, reduced development, reduced adult weight, reduced reproductive performance, decreased longevity, and increased mortality (Tingey, 1991). Glandular trichomes have been bred into cultivated potato from the wild species $S$. berthaultii and are available as a breeding line NYL235-4 (Plaisted et al., 1992).

Glycoalkaloids are the most common form of antibiosis in potato (Sinden et al., 1986a). Steroidal glycoalkaloids (solanine and chaconine) are present in all potato plant parts, including the tubers, and may cause human health concerns if present at high levels (Sinden, 1987). Glycoalkaloid levels below 20 mg/100 g FW 
Table 1. Potato lines indicating plant resistance mechanism.

\begin{tabular}{|c|c|c|c|c|}
\hline $\begin{array}{l}\text { Host plant } \\
\text { resistance } \\
\text { mechanism }\end{array}$ & Construct $^{2}$ & Source $^{\mathrm{y}}$ & $\begin{array}{l}\text { Parent } \\
\text { clone }\end{array}$ & $\begin{array}{l}\text { Potato } \\
\text { clone }\end{array}$ \\
\hline Leptine glycoalkaloids & None & USDA-ARS & $\mathrm{NA}^{\mathrm{x}}$ & USDA8380-1 \\
\hline CPB resistant (glycoalkaloids) & None & NDSU & NA & ND5873-15 \\
\hline Glandular trichomes & None & Cornell & NA & NYL235-4 \\
\hline \multirow[t]{3}{*}{$B t$-cry $3 A$} & CaMV35S/cry3A & NMSU & Russet Burbank & RBN15 \\
\hline & CaMV35S/cry $3 A$ & NatureMark & Russet Burbank & RB Newleaf \\
\hline & ocs $_{3}$ mas/cry $3 \mathrm{~A}$ & MSU & Yukon Gold & YGc3.1 \\
\hline Bt-cry5 & CaMV35S/cry5 & MSU & Spunta & SPc5-G2 \\
\hline Glandular trichomes $+B t$-cry 5 & CaMV35S/cry5/gus & MSU & NYL235-4 & NYL235-4c5.13 \\
\hline Susceptible control & None & NA & NA & Russet Burbank \\
\hline
\end{tabular}

zTransgene construct information: $C a M V 35 S=35$ S cauliflower mosaic virus promoter; ocs 3 mas $=$ trimer octopine synthase and mannopine activator and promoter; cry $3 A=B t$-cry $3 A$ is a coleopteran-specific insecticidal crystal protein gene; $c r y 5=B t$-cry 5 is a lepidopteran and coleopteran-specific insecticidal crystal protein gene; gus = beta-galacturonidase reporter gene; none $=$ nontransgenic potato line.

${ }^{y}$ Source: USDA-ARS = Beltsville, Md.; NDSU = North Dakota State University; Cornell = Cornell University; NMSU = New Mexico State University; NatureMark is a subsidiary of the Monsanto Corporation; MSU = Michigan State University.

${ }^{\mathrm{x}} \mathrm{NA}=$ not applicable.

$(\mathrm{mg} \%)$ are considered safe for human consumption. Solanum tuberosum generally contains only 2 to $10 \mathrm{mg} \%$ glycoalkaloids. Leptines are the most active form of glycoalkaloids present in potato for insect control (Lawson et al., 1993) and demonstrate antifeedant properties against colorado potato beetle at concentrations as low as $100 \mathrm{mg} \%$ (Sanford et al., 1996). Leptines and other acetylated glycoalkaloids are reported to be synthesized by only a few accessions of S. chacoense Bitter (Sanford et al., 1996). Human health concerns about high glycoalkaloids are not an issue as leptines are synthesized and present only in the leaves and not the tubers (Sanford et al., 1996). The high leptine-producing accession of $S$. chacoense, USDA8380-1 (PI 458310), is a diploid selection containing $\approx 300 \mathrm{mg} \%$ leptines (constituting $90 \%$ of the total glycoalkaloids) with strong antifeedant properties against colorado potato beetle (Deahl et al., 1991; Sinden et al., 1986a).

These natural host plant resistance mechanisms, combined with engineered $B t$-transgenic resistance, could increase the durability and efficacy of potato host plant resistance to the colorado potato beetle. The objective of this study was to evaluate various natural, engineered, and combined host plant resistance mechanisms in potato for control of colorado potato beetle under field conditions.

\section{Materials and Methods}

Nine different potato clones representing five different host plant resistance mechanisms were evaluated in a choice situation under natural colorado potato beetle pressure at the Montcalm Research Farm in Entrican, Mich. Table 1 describes the vector construct, source, and parent clones of the plant resistance mechanisms. Nontransgenic potato clones included: USDA8380-1 (S. chacoense Bitter P.I. 458310) with high foliar leptines (provided by L. Sanford, USDA-ARS, Beltsville, Md.); ND5873-15 with high foliar total glycoalkaloids (TGA) (data not shown) (provided by R. Novy and J. Lorenzen at North Dakota State University); NYL235-4 with glandular trichomes (Plaisted et al., 1992); and 'Russet Burbank'.

The two Bt genes used were Bt-cry3A (coleopteran specific) and Bt-cry5 (Bt-crylIal) (leptidopteran and coleopteran specific). The $B t$-cry3A transgenic potato clones used in this study included Btcry3A-Russet Burbank (RBN15) provided by J. Kemp at New Mexico State University; 'Russet BurbankNewleaf' (NatureMark); and the Bt-cry3A-Yukon Gold (YGc3.1) developed in our labora- tory (Coombs et al., 2002). The Bt-cry5 transgenic clones used were SPc5-G2 (Douches et al., 2002) and NYL235-4c5.13, developed in our laboratory via Agrobacterium tumefaciens transformation as described by Douches et al. (1998). The synthetic Bt-cry3A gene used was supplied by J. Kemp at New Mexico State University (Sutton et al., 1992). The codon-modified Bt-cry5 gene was provided by Syngenta (formerly Zeneca) (Tailor et al., 1992).

All potato lines were maintained in tissue culture by nodal propagation in $25 \times 150 \mathrm{~mm}$ culture tubes or GA-7 Magenta vessels (Magenta Corp., Chicago, Ill.) in modified Murashige and Skoog (1962) medium [4.3 g. $\mathrm{L}^{-1}$ MS salts, 3\% sucrose, $1.4 \mathrm{~mm}$ sodium phosphate, $1.1 \mu \mathrm{m}$ thiamine, $0.55 \mathrm{~mm}$ myo-inositol, $\mathrm{pH}$ 6.0, $8 \mathrm{~g} \cdot \mathrm{L}^{-1}$ Bactoagar (Difco, Detroit, Mich.)], and sealed with Micropore surgical tape (3M Company, St. Paul, Minn.). The tissue culture growth environment was $16 / 8 \mathrm{~L} / \mathrm{D}$ photoperiod under 30 $\mu \mathrm{mol} \cdot \mathrm{m}^{-2} \cdot \mathrm{s}^{-1}$ fluorescent bulbs at $25 \pm 2{ }^{\circ} \mathrm{C}$. Tissue culture plants were transplanted to greenhouse trays ( 50 per tray, $3 \mathrm{~cm}$ diameter), grown for four weeks in the greenhouse, and then transplanted to the field in 1998. Tubers were saved from the 1998 trial and used as seed for the 1999 trial, with the exception of USDA8380-1 (a nontuberizing line under long-day conditions), which were grown as tissue culture-derived transplants.

Field trials were conducted in 1998 and in 1999 at the Michigan State University Montcalm Research Farm in Entrican, Mich. A randomized complete block design consisting of four replications of 10 plants each was used. Treatment plots $(25.4 \mathrm{~cm}$ plant spacing) were planted between alternating rows $(86.4 \mathrm{~cm}$ row spacing) of a susceptible guard, 'Snowden'. In 1998, greenhouse-grown tissue culture plantlets were transplanted to the field. In 1999, tuber seed pieces ( $\approx 57 \mathrm{~g}$ each) were planted, except USDA8380-1, which was handled as previously mentioned. Observations were recorded about weekly for a visual estimation of percent defoliation by colorado potato beetles, number of egg masses, and number of first, second, third, fourth instars, and adults per plant. Data were collected until vine senescence; from 1 July to 8 Aug. (42 d) in 1998 and from 17 June to 26 July (39 d) in 1999.

The colorado potato beetle population at the Montcalm Research Farm is known to be resistant to most insecticides including organochlorines, organophosphates, carbamates, and pyrethroids; and is similar to most colorado potato beetle populations found in commercial potato plantings in Michigan (Ioannidis et al., 1991). This 
Table 2. Analysis of variance for defoliation and lifestage data of potato lines from field evaluations of natural host plant resistance mechanisms of potato for control of colorado potato beetle.

\begin{tabular}{lccc}
\hline \hline $\begin{array}{c}1998 \\
\text { Response }^{\mathrm{z}}\end{array}$ & $\begin{array}{c}1999 \\
(P \text { value })\end{array}$ & $\begin{array}{c}\text { Spearman's } \\
(P \text { value })\end{array}$ & $\begin{array}{c}\text { rank correlation } \\
\text { for 1998-99 }(r)\end{array}$ \\
\hline $\begin{array}{l}\text { Defoliation } \\
\text { RAUDC }\end{array}$ & & & \\
$\begin{array}{l}\text { Lifestage } \\
\text { Egg masses }\end{array}$ & 0.0001 & 0.0001 & $1.000^{*}$ \\
$\quad$ First instar & NS & 0.0378 & $0.983^{*}$ \\
Second+third instar & 0.0056 & $\mathrm{NS}$ & 0.417 \\
$\quad$ Fourth instar & 0.0002 & 0.0024 & $0.833^{*}$ \\
Adult & 0.0059 & 0.0001 & $0.761^{*}$ \\
\hline
\end{tabular}

$\overline{{ }^{\mathrm{Z}} \text { Response }}=$ All lifestage data based on calculation of seasonal cumulative number of individuals per plant. Defoliation was also calculated on a per plant basis.

' $\mathrm{RAUDC}=$ relative area under the defoliation curve values.

Ns, ${ }^{*}$ Nonsignificant or significant at $\alpha=0.05$.

research site has been maintained and used for various colorado potato beetle field studies since the 1970s.

Application of fertilizer, fungicide, and irrigation were applied according to standard best management practices. Insecticides were not used, with the exception of dimethoate, which was applied as needed to control potato leaf hoppers (Empoasca fabae Harris). Dimethoate has not shown any noticeable effect on the colorado potato beetle population at the Montcalm Research Farm (Grafius, personal communication). This trial location has been planted in a potato-on-potato system for $>20$ years. Potato vines at this site tend to senesce in early August and also exhibit symptoms of the potato early die complex. Observations of these plots before early August effectively differentiate resistant and susceptible lines caused by overwintered adults, first generation larvae, and subsequent generation adults.

Data were analyzed by using SAS general linear model procedure for analysis of variance (SAS, 2000). Mean comparisons were conducted using Fisher's least significant difference $(\alpha=0.05)$. Percent defoliation data were used to calculate the area under the defoliation curve (AUDC), based on calculation of the area under the disease progress curve (Shaner and Finney, 1977), and divided by the maximum AUDC (e.g., 3300 for $33 \mathrm{~d}$ after initial observation of defoliation), converting the value to relative AUDC (RAUDC). Seasonal cumulative mean number of colorado potato beetles per plant was calculated by dividing the cumulative number of individuals per plant by the number of observational dates. Rank correlation of the potato clones for defoliation was determined by Spearman's Rank Correlation procedure at $\alpha=0.05$ (SAS, 2000).

\section{Results and Discussion}

Defoliation Results. Analysis of variance showed that there were significant differences between the host plant resistant potato clones for relative area under the defoliation curve (RAUDC) (Table 2). In general, greater percent defoliation was observed in 1998 than 1999 (Fig. 1). The increased feeding in 1998 could, in part, be due to the plants being tissue culture plantlets, and they were transplanted into the field at a later date (less vigorous in comparison to plants grown from seed pieces). However, the Spearman Rank Correlation analysis results showed a significant correlation $(r=1.000 ; P(0.0001)$ for the ranked order of the different potato clones for RAUDC values between years (Table 2) indicating RAUDC is a consistent measure of host plant between years.

The susceptible control cultivars showed defoliation typical of that expected from nonpesticide use on cultivars for this site (Grafius, unpublished data). The three Bt-cry $3 A$ transgenic lines and high leptine expressing line (USDA8380-1) were most effective for limiting defoliation (RAUDC of 0.005 to 0.036 in 1998 and 0.000 to 0.003 in 1999) by colorado potato beetle adults and larvae throughout the field season (Fig. 1). Among the Bt-cry3A lines, no differences were observed despite the Bt-cry $3 A$ gene being expressed using two different constitutive promoters. The commercial cultivar, 'Russet Burbank Newleaf,' and RBN15 are lines that express the codon-modified Bt-cry3A gene with the CaMV35S promoter, while the Bt-cry3A Yukon Gold (YGc3.1) uses the (ocs) ${ }_{3}$ mas promoter (Coombs et al., 2002). USDA8380-1 has been previously reported to have lower feeding and less preference in both field (Sinden et al., 1986a) and laboratory bioassays (Sinden et al., 1986b) compared to cultivated potato lines. The high foliar TGA breeding line (ND5873-15) also limited defoliation during the season (Fig. 1). This TGA line had slightly more feeding than any of the Bt-cry $3 A$ or leptine lines, although they were not significantly different.

In general, the two Bt-cry5 lines were not as effective as the $B t$ cry $3 A$ transgenic lines, although one $B t$-cry 5 transgenic (SPc5-G2) had significantly lower defoliation than the other Bt-cry5 line (NYL235-4c5.13) (Fig. 1). Tailor et al. (1992) reported Bt-cry5 to have both lepidopteran and coleopteran activity. SPc5-G2 was reported to be highly effective in limiting potato tuber moth (Phthorimaea operculella Zeller) feeding in tubers (Mohammed et al., 2000) and foliage (Douches et al., 2002). Previous detached-leaf bioassays in our laboratory have shown most Bt-cry 5 transgenic potato lines to have little effect on feeding of colorado potato beetles in no-choice studies (Douches et al., 2001). However, the detachedleaf studies did indicate reduced feeding on the Bt-cry5 transgenic

Fig. 1. Relative area under the defoliation curve (RAUDC) of colorado potato beetles on host plant resistant potato clones.

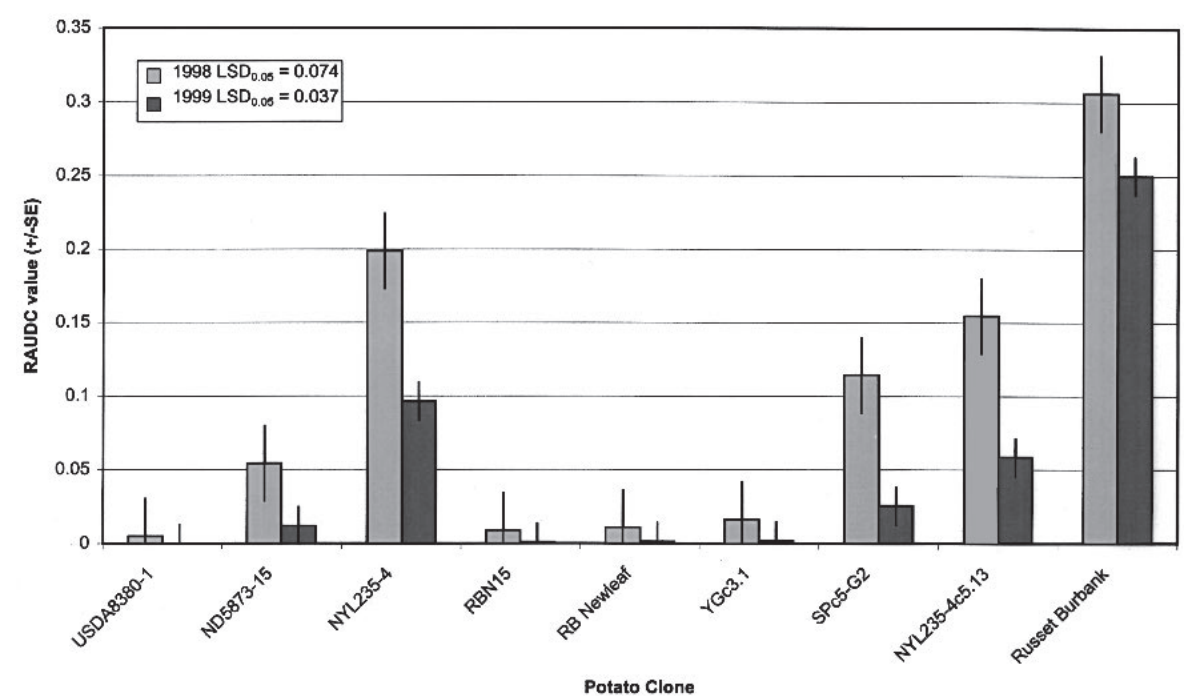




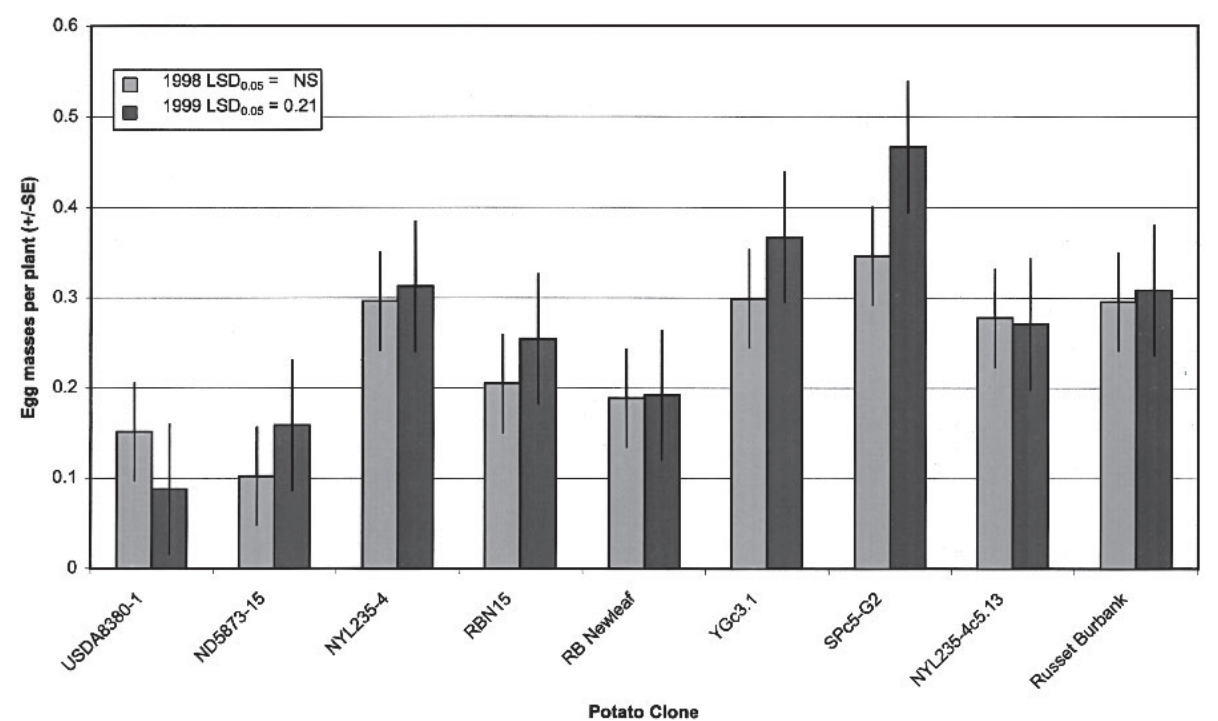

Fig. 2. Seasonal mean cumulative number of colorado potato beetle egg masses per plant on host plant resistant potato clones.

line SPc5-G2 compared to susceptible controls. The glandular trichome line (NYL235-4) and Bt-cry5+glandular trichome lines proved to be ineffective in this field study. These results are in contrast to a previous field study evaluating glandular trichomebased resistance (Tingey and Yencho, 1994). The lack of resistance observed using NYL235-4 as the glandular trichome host plant resistance source may be due to multiple factors. NYL235-4 is a result of a series of six backcrosses from the wild $S$. berthaultii (Plaisted et al., 1992). Backcrossing resulted in reduced type A and B trichome densities. Plaisted et al. (1992) had shown NYL235-4 to be effective in controlling feeding and reduced egg laying and increased first and second instar mortality. Our results may differ due to the colorado potato beetle populations and combination of multiple and different host plant resistant mechanisms interacting. In addition, the combined glandular trichomes+Bt-cry5 line, (NYL235-4c5.13), may have had low Bt-cry5 expression due to the gus gene being fused to the Bt-cry5 gene in the vector construct (Westedt et al., 1998).

LifE STAGE RESULTS. All life stage results are reported as the seasonal cumulative mean number of individuals per plant, calculated by summing the mean number of individuals per plant over the season for each clone, and dividing by the number of dates that observations were recorded. Analysis of variance for the seasonal cumulative mean number of colorado potato beetles at each life stage was significantly different across potato lines for each year, with three exceptions: 1) the number of egg masses per plant in 1998,2 ) the number of first instars per plant in 1999, and 3) number of fourth instars per plant in 1999 (Table 2).

In general, egg laying seasonal cumulative means were distributed among the lines, however, the number of egg masses per plant on the high TGA line and USDA8380-1 had fewer egg masses in 1999 as compared to the susceptible cultivars (Figs. 2 and 3). This observation seems to be associated with the deterrent activity of the glycoalkaloids (Sinden et al., 1986a). In 1998, under natural infesta- tion, there were no differences for the number of egg masses across potato lines.

Similar to the egg laying results, seasonal cumulative mean number of first instars per plant were distributed among the lines. The rank correlation for the seasonal cumulative means for first instars was nonsignificant between years. However, in 1998 there was a significant difference among lines, but not in 1999 (Table 2). Fewer first instars were observed on the high total glycoalkaloid (ND5873-15) and leptine(USDA8380-1) lines (Fig. 3). These results are expected because there was less egg laying on these lines.

The second and third instars were combined at the time of data collection as these two instars were the most difficult to accurately distinguish from each other. Between the two years, the rank correlation was significant $(r=0.833 ; P(0.0053)$ (Table 2$)$. With the seasonal cumulative mean of second and third instar data, a pattern begins to emerge among the host plant resistance mechanisms. The susceptible varieties have the most surviving larvae (Fig. 4). Meanwhile, the leptine line and the three $B t$-cry $3 A$ lines had few surviving larvae. The mean for SPc5-G2, the Bt-cry5 line, NYL235-4, and NYL235$4 c 5.13$ were similar to the susceptible cultivars. The high TGA line had fewer larvae than the susceptible cultivars.

As with the second and third instar seasonal cumulative means, the fourth instar seasonal cumulative means of the lines had a significant rank correlation but less than the second and third instar seasonal cumulative means (Table 2). The lower rank correlation may be attributed to the greater mobility of the fourth instars. Again the susceptible cultivars and the glandular trichome lines (NYL2354 and NYL235-4c5.13) were similar in fourth instar seasonal cumulative means (Fig. 5). However, the contrast between the susceptible varieties and the three $B t$-cry $3 A$ lines and the leptine line was greater. These resistant lines had few, if any surviving fourth instars. Any observed second and third or fourth instars on the Btcry $3 A$ lines appeared to have moved onto the plants from adjacent susceptible plants. Second and third and fourth instars observed on

Fig. 3. Seasonal mean cumulative number of colorado potato beetle first instars per plant on host plant resistant potato clones.

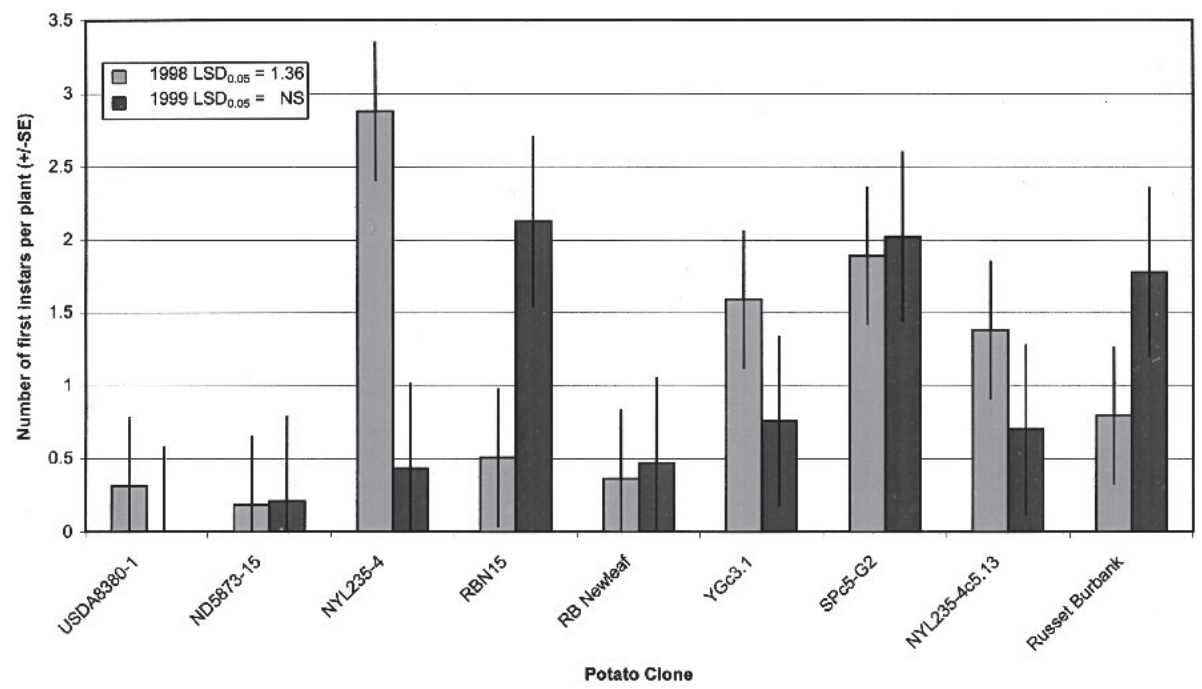




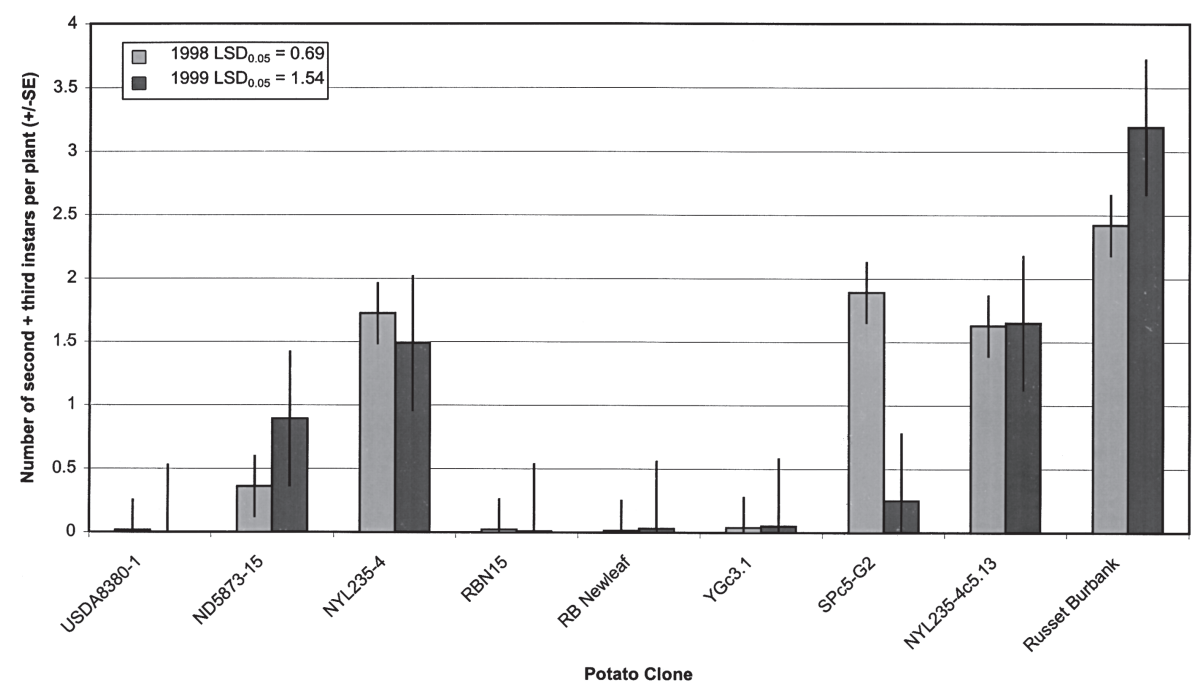

Fig. 4. Seasonal mean cumulative number of colorado potato beetle second + third instars per plant on host plant resistant potato clones.

the high total glycoalkaloid and Bt-cry5 lines could also have been from movement; however, they appeared to be less morbid as compared to those on the Bt-cry $3 A$ lines.

In 1999, there were a greater number of adults than in 1998 and the rank correlation of the lines for adult cumulative means was not significant (Table 2). Because of the mobility of the adult life stage, the adults were found on all lines, but more on the susceptible varieties (Fig. 6). It was surprising to observe the high numbers of the adults on the glandular trichome lines. Data from this life stage demonstrate that there was little preference of the adults among the lines at this time of the field season (mid-July). Some of the differences in life stage data are probably due to the use of transplants in 1998 versus seed pieces in 1999 to establish the plots. For example, in 1998, with transplants, there was greater feeding but fewer colorado potato beetles at all life stages. In contrast, in 1999, with plants grown from seed pieces which are more vigorous, there was less defoliation, even with the observation of more colorado potato beetles.

VALUE OF HOST PLANT RESISTANCE SOURCES FOR BREEDING. Leptines and Bt-cry $3 A$ were most effective against defoliation by colorado potato beetle adults and larvae. The leptine-based resistance was found in a selection from the diploid wild potato species $S$. chacoense (Sinden et al., 1986a). Long stolons rather than tubers are formed during the season under long-day conditions. It is highly unadapted to the summer photoperiod in Michigan. With numerous rounds of crossing and selection followed by interploidy crosses, the leptine-based resistance could be incorporated into advanced cultivated tetraploid germplasm. The Bt-cry $3 \mathrm{~A}$ gene has been found to be an effective plant resistance mechanism (Adang et al., 1993; Perlak et al., 1993; Sutton et al., 1992). Currently, a high-dose strategy with use of refugia is considered the best deployment of Bt-cry3A (McGaughy and Whalon, 1992) in potato production. Our breeding approach is to target advanced breeding lines that are to be commercialized for Bt-cry $3 \mathrm{~A}$ transformation to deploy the $B t$-Cry3A protein. The total glycoalkaloid line (ND5873-15) is also effective, but we observed some feeding during the season. It is a tetraploid advanced selection that has a very late maturity. With further cycles of crossing and selection, advanced breeding lines with commercial potential could be released that exploit the TGA-based resistance.

The glandular trichome line, NYL235-4, was not effective against the colorado potato beetle compared to the Bt-cry3A, leptines or total glycoalkaloids. NYL235-4has been more of a deterrent to feeding early in the season, when more susceptible plants are more prevalent. Later in the season when less amounts of susceptible foliage are present, more feeding on NYL235-4 is observed (unpublished data). Potato leaf hopper (Empoasca fabae Harris) damage did not occur in the glandular trichome plots (data not shown). A possible strategy is to combine the Bt-cry $3 A$ with the glandular trichomes so that both host plant resistances to colorado potato beetle and the smaller-bodied potato insect pests such as potato leaf hopper could be achieved in a single cultivar.

Defoliation over time is the best estimate of the host plant's resistance against colorado potato beetle. Defoliation, at a certain threshold, leads to significant yield loss (Hare, 1980). Therefore, the use of the RAUDC was the best measure of host plant resistance for this study. The life stage evaluations provide a complimentary set of data. From the egg mass seasonal cumulative means and adult feeding, we were able to observe host preference. Valuable field information on mortality and survival is found when egg masses have been laid. The larvae hatched on the host plants will have typical development, be slowed or die.

We evaluated five different host plant resistance mechanisms of potato under a single choice field experiment that have been previously studied individually. This study allowed us to compare and rank these different host plant resistance mechanisms. The Btcry $3 A$, foliar total glycoalkaloids and leptine resistances have potential to be used as host plant resistance sources in a breeding

Fig. 5. Seasonal mean cumulative number of colorado potato beetle fourth instars per plant on host plant resistant potato clones.

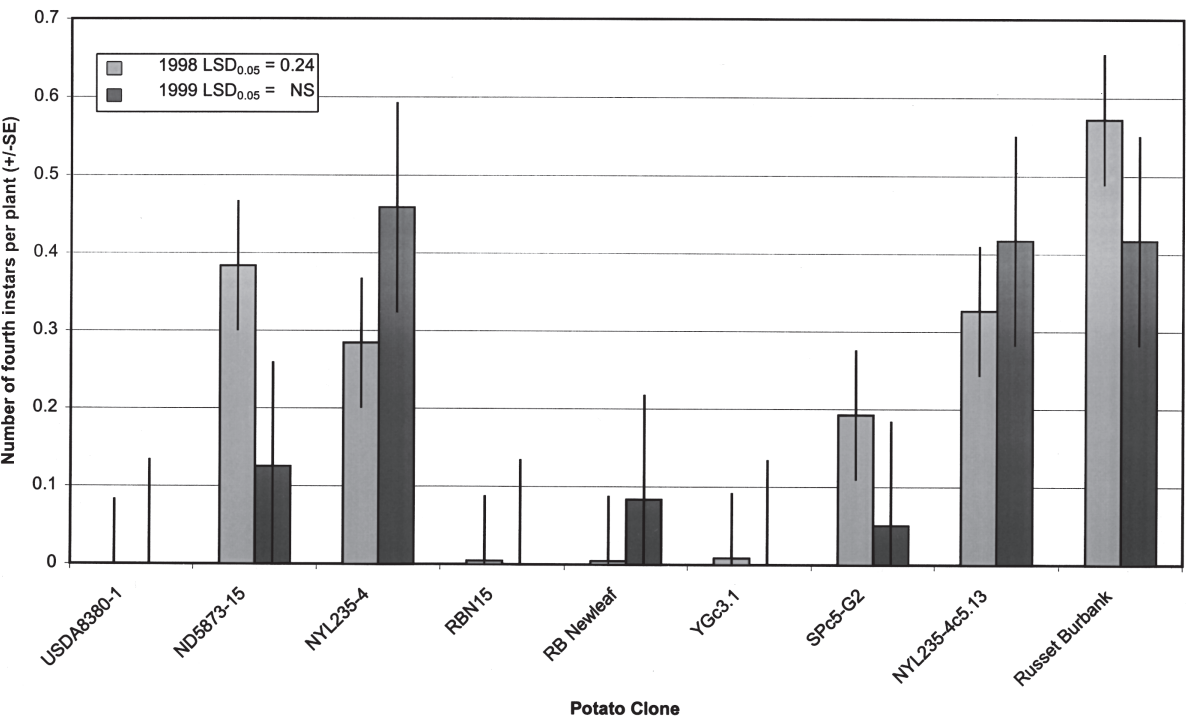




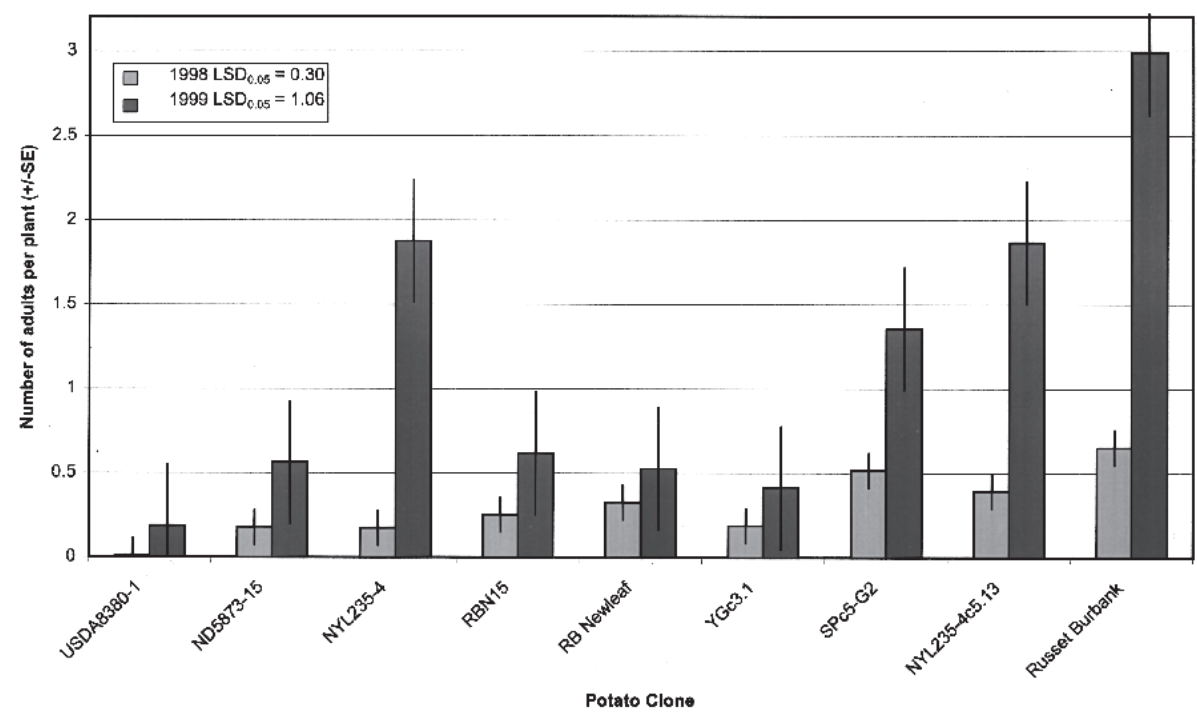

Fig. 6. Seasonal mean cumulative number of colorado potato beetle adults per plant on host plant resistant potato clones.

program. Further research needs to be done to compare these resistances in the field in no-choice studies. Our continued research efforts will be toexamine the natural (leptines and total glycoalkaloids) and engineered (Bt-cry3A) plant resistances combined in single plants.

\section{Literature Cited}

Adang, M.J., M.S. Brody, G. Cardineau, N. Eagan, R.T. Roush, C.K. Shewmaker, A. Jones, J.V. Oakes, and K.E. McBride. 1993. The reconstruction and expression of a Bacillus thuringiensis cry $3 A$ gene in protoplasts and potato plants. Plant Mol. Biol. 21:1131-1145.

Barton, K.A. and M.J. Miller. 1993. Production of Bacillus thuringiensis insecticidal proteins, p. 297-315. In: S. Kung and R. Wu (eds.). Transgenic plants. vol. 1. Engineering and utilization. Academic Press, San Diego, Calif.

Casagrande, R.A. 1982. Colorado potato beetle resistance in a wild potato, Solanum berthaultii. J. Econ. Entomol. 75:368-372.

Casagrande, R.A. 1987. The colorado potato beetle: 125 years of mismanagement. Bul. Entomol. Soc. Amer. 18:142-150.

Coombs, J., D. Douches, W. Li, E. Grafius, and W. Pett. 2002. Combining engineered (Bt-cry3A) and natural resistance mechanisms in potato for control of colorado potato beetle. J. Amer. Soc. Hort. Sci. 127:62-68.

Crickmore, N., D.R. Zeigler, E. Schnepf, J. Van Rie, D. Lereclus, J. Baum, A. Bravo, and D.H. Dean, 2002. Bacillus thuringiensis toxin nomenclature. http:// www.biols.susx.ac.uk/Home/Neil_Crickmore/Bt/index.html (21 March 2002).

Deahl, K.L., W.W. Cantelo, S.L. Sinden, and L.L. Sanford. 1991. The effect of light intensity on colorado potato beetle resistance and foliar glycoalkaloid concentration of four Solanum chacoense clones. Amer. Potato J. 68:659-666.

Douches, D.S., A.L. Westedt, K. Zarka, B. Schroeter, and E.J. Grafius. 1998. Potato transformation to combine natural and engineered resistance for controlling tuber moth. HortScience 33:1053-1056.

Douches, D.S., T.J. Kisha, W. Li, W.L. Pett, and E.J. Grafius. 2001. Effectiveness of natural and engineered host plant resistance in potato to the colorado potato beetle [Leptinotarsa decemlineata (Say)]. HortScience 36:967-970.

Douches, D.S., W. Li, K. Zarka, J. Coombs, W.L. Pett, E.J. Grafius, and T. El-Din. 2002. Germplasm release of Bt-cry5 Spunta, insect resistant potato lines G2 and G3. HortScience 37(7):1103-1107.

Forgash, A.J. 1985. Insecticide resistance in the colorado potato beetle, p. 33-52. In: D.N. Ferro and R.H. Voss (eds.). Proc. Symp. of the Colorado Potato Beetle. XVIII ${ }^{\text {hh }}$ Intl. Congr. Entomol. Mass. Agr. Expt. Sta. Bul. 704.

Georgiou, G.P., and A. Lagunes-Tejeda. 1991. The occurrence of resistance to pesticides in arthropods. FAO of the United Nations. Rome. p. 318.

Gregory, P., W.M. Tingey, D.A. Ave, and P.Y. Bouthyette. 1986. Potato glandular trichomes: A physicochemical defense mechanism against insects, In: M.B. Green, and P.A. Hedin (eds.). Natural resistance of plant pests. ACS Symp. Ser.
296. ACS Books, Wash., D.C.

Hare, J.D. 1980. Impact of defoliation by the colorado potato beetle on potato yields. J. Econ. Entomol. 73:369373.

Ioannidis, P.M., E. Grafius, and M.E. Whalon. 1991. Patterns of insecticide resistance to azinphosmethyl, carbofuran, and permethrin in colorado potato beetle (Coleoptera: Chrysomelidae). J. Econ. Entomol. 84:1417-1423.

Lambert, B. and M. Peferoen. 1992. Insecticidal promise of Bacillus thuringiensis. BioScience 42:112-122.

Lawson, D.R., R.E. Veilleux, and A.R. Miller. 1993. Biochemistry and genetics of Solanum chacoense steroidal alkaloids: Natural resistance factors to the colorado potato beetle. Current Topics Bot. Res. 1:335-352.

McGaughey, W.H. and M.E. Whalon. 1992. Managing insect resistance to Bacillus thuringiensis toxins. Science 285:1451-1454.

Mohammed, A., D.S. Douches, W. Pett, E. Grafius, J. Coombs, Liswidowati, W.Li, and M.A. Madkour. 2000. Evaluation of potato tuber moth (Lepidoptera: Gelechiidae) resistance in tubers of Bt-cry 5 transgenic potato lines. J. Econ. Entomol. 93:472-476.

Murashige, T. and F. Skoog. 1962. A revised medium for rapid growth and bioassays with tobacco tissue cultures. Physiol. Plant. 15:473-497.

Perlak, F.J., T.B. Stone, Y.M. Muskopf,L.J.Petersen, G.B.Parker, S.A. McPherson, J. Wyman, S. Love, G. Reed, D. Biever, and D.A. Fischhoff. 1993. Genetically improved potatoes: protection from damage by colorado potato beetles. Plant Mol. Biol. 22:313-321.

Plaisted, R.L., W.M. Tingey, and J.C. Steffens. 1992. The germplasm release of NYL235-4, a clone with resistance to the colorado potato beetle. Amer. Potato J. 69:843-846.

Sanford, L.L., R.S. Kobayashi, K.L. Deahl, and S.L. Sinden. 1996. Segregation of leptines and other glycoalkaloids in Solanum tuberosum $(4 \mathrm{x}) \times$ S. chacoense $(4 \mathrm{x})$ crosses. Amer. Potato J. 73:21-33.

SAS Institute. 2000. The SAS system for Windows. release 8.01. SAS Inst., Inc. Cary, N.C.

Shaner, G. and R.E. Finney. 1977. The effect of nitrogen fertilization on the expression of slow-mildewing resistance in Knox wheat. Phytopathology 67:10511056.

Sinden, S.L. 1987. Potato glycoalkaloids. Acta Hort. 207:41-47.

Sinden, S.L., L.L. Sanford, W.W. Cantelo, and K.L. Deahl. 1986a. Leptine glycoalkaloids and resistance to the colorado potato beetle (Coleoptera: Chrysomelidae) in Solanum chacoense. Environ. Entomol. 15:1057-1062.

Sinden, S.L., L.L. Sanford, and K.L. Deahl. 1986b. Segregation of leptine glycoalkaloids in Solanum chacoense Bitter. J. Agr. Food Chem. 34:372-377.

Sutton, D.W., P.K. Havstad, and J.D. Kemp. 1992. Synthetic cry3A gene from Bacillus thuringiensis improved for high expression in plants. Transgenic Res. 1:228-236.

Tailor, R., J. Tippet, G. Gibb, S. Pells, D. Pike, L. Jordan, and S. Ely. 1992. Identification and characterization of a novel Bacillus thuringiensis (endotoxin entomocidal to coleopteran and lepidopteran larvae. Mol. Microbiol. 6:12111217.

Tingey, W.M. 1991. Potato glandular trichomes: Defense activity against insect attack, p. 126-135. In: P.A. Hedin (ed.). Naturally occurring pest bioregulators. Amer. Chem. Soc. Symp. Ser. 449. ACS Books, Wash., D.C.

Tingey, W.M. and G.C. Yencho. 1994. Insect resistance in potato: A decade of progress, p. 405-425. In: G.W. Zehnder, M.L. Powelson, R.K. Jansson, and K.V. Raman (eds.). Advances in potato pest biology and management. APS Press, St. Paul, Minn.

Westedt, A., D.S. Douches, W. Pett, and E.J. Grafius. 1998. Evaluation of natural and engineered resistance mechanisms in Solanum tuberosum for resistance to Phthorimaea operculella (Lepidoptera: Gelechiidae). J. Econ. Entomol. 91:552_556.

Wright, R.J., M.B. Dimock, W.M. Tingey, and R.L. Plaisted. 1985. Colorado potato beetle (Coleoptera: Chrysomelidae): expression of resistance in Solanum berthaultii and interspecific potato hybrids. J. Econ. Entomol. 78:576-582.

Yencho, C.G. and W.M. Tingey. 1994. Glandular trichomes of Solanum berthaultii alter host preference of the colorado potato beetle, Leptinotarsa decemlineata. Entomol. Expt. Appl. 70: 217-225. 